\title{
Major haplotype divergence including multiple germin-like protein genes, at the wheat Sr2 adult plant stem rust resistance locus
}

Rohit Mago ${ }^{1 \dagger}$, Linda Tabe ${ }^{1 \dagger}$, Sonia Vautrin², Hana Šimková3, Marie Kubaláková3 ${ }^{2}$ Narayana Upadhyaya ${ }^{2}$, Hélène Berges ${ }^{2}$, Xiuying Kong ${ }^{4}$, James Breen ${ }^{5,6}$, Jaroslav Doležel ${ }^{3}$, Rudi Appels ${ }^{5}$, Jeffrey G Ellis ${ }^{1}$ and Wolfgang Spielmeyer ${ }^{1 *}$

\begin{abstract}
Background: The adult plant stem rust resistance gene Sr2 was introgressed into hexaploid wheat cultivar (cv) Marquis from tetraploid emmer wheat cv Yaroslav, to generate stem rust resistant cv Hope in the 1920s. Subsequently, Sr2 has been widely deployed and has provided durable partial resistance to all known races of Puccinia graminis f. sp. tritici. This report describes the physical map of the Sr2-carrying region on the short arm of chromosome 3B of cv Hope and compares the Hope haplotype with non-Sr2 wheat cv Chinese Spring.

Results: Sr2 was located to a region of 867 kb on chromosome 3B in Hope, which corresponded to a region of $567 \mathrm{~kb}$ in Chinese Spring. The Hope Sr2 region carried 34 putative genes but only 17 were annotated in the comparable region of Chinese Spring. The two haplotypes differed by extensive DNA sequence polymorphisms between flanking markers as well as by a major insertion/deletion event including ten Germin-Like Protein (GLP) genes in Hope that were absent in Chinese Spring. Haplotype analysis of a limited number of wheat genotypes of interest showed that all wheat genotypes carrying Sr2 possessed the GLP cluster; while, of those lacking Sr2, some, including Marquis, possessed the cluster, while some lacked it. Thus, this region represents a common presence-absence polymorphism in wheat, with presence of the cluster not correlated with presence of Sr2. Comparison of Hope and Marquis GLP genes on 3BS found no polymorphisms in the coding regions of the ten genes but several SNPs in the shared promoter of one divergently transcribed GLP gene pair and a single SNP downstream of the transcribed region of a second GLP.
\end{abstract}

Conclusion: Physical mapping and sequence comparison showed major haplotype divergence at the Sr2 locus between Hope and Chinese Spring. Candidate genes within the Sr2 region of Hope are being evaluated for the ability to confer stem rust resistance. Based on the detailed mapping and sequencing of the locus, we predict that Sr2 does not belong to the NB-LRR gene family and is not related to previously cloned, race non-specific rust resistance genes Lr34 and Yr36.

Keywords: Adult plant resistance (APR), Map-based cloning, Sr2, Germin-like proteins (GLPs), Wheat stem rust, Puccinia graminis, Physical mapping, Gene expression

\section{Background}

Wheat stem rust caused by the fungal pathogen Puccinia graminis Pers. f. sp. tritici (Pgt) is a major worldwide threat to wheat crops. The re-appearance of stem rust epidemics in East Africa and their spread eastward to Yemen and Iran, based on Ug99- a wheat stem rust isolate virulent on a large proportion of the world's current

\footnotetext{
* Correspondence: wolfgang.spielmeyer@csiro.au

${ }^{\dagger}$ Equal contributors

'CSIRO Agriculture Flagship, Canberra, ACT 2601, Australia

Full list of author information is available at the end of the article
}

wheat varieties, has alarmed the global wheat community $[1,2]$. More recently, new epidemics of stem rust caused by a different race of Pgt have been reported in Germany and Ethiopia (2013-2014; http://rusttracker. cimmyt.org/?page_id=40) reiterating the need to identify new resistance genes against rust pathogens, and to understand the mechanism of resistance, which may lead to development of novel strategies for crop protection.

Highly effective stem rust resistance was introgressed into hexaploid wheat cv, Marquis from the rust-resistant, cultivated emmer wheat cv Yaroslav from crosses initiated in

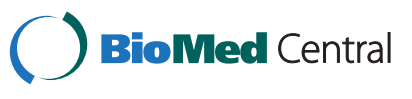

(c) 2014 Mago et al.; licensee BioMed Central. This is an Open Access article distributed under the terms of the Creative Commons Attribution License (http://creativecommons.org/licenses/by/4.0), which permits unrestricted use, distribution, and reproduction in any medium, provided the original work is properly credited. The Creative Commons Public Domain Dedication waiver (http://creativecommons.org/publicdomain/zero/1.0/) applies to the data made available in this article, unless otherwise stated. 
1916 by American breeder E.S. McFadden. Crosses were made between Yaroslav emmer and several varieties of hard red spring wheat, but were only successful with cv Marquis. Several years of selection for stem rust resistance, quality and yield among progeny derived from a single $\mathrm{F}_{1}$ plant resulted in the selections $\mathrm{H}_{44-24}, \mathrm{H}_{29-24}$ and $\mathrm{H}_{35-24}$. The line $\mathrm{H}_{29-24}$ was later released as the variety Hope [3]. High levels of field resistance against Pgt were observed in Hope and $\mathrm{H}_{44-24}$ (later re-named $\mathrm{H} 44$ ). This source of stem rust resistance was then used widely in the US, Australian and CIMMYT wheat breeding programs. McIntosh et al. [4] and Knott [5] genetically characterised the basis of resistance in Hope and H44, and identified three race-specific genes; $S r 7 b$ from the Marquis parent, and $S r 9 d$ and $S r 17$ from Yaroslav. In addition Hare and McIntosh [6] described an adult plant, partial resistance gene, $S r 2$, effective against all tested Pgt strains. Using substitution lines carrying each Hope chromosome in Chinese Spring, Hare and McIntosh [6] mapped Sr2 to chromosome arm 3BS. Selection in breeding programs for high levels of field resistance to stem rust derived from cv Hope combined $\mathrm{Sr} 2$ with various seedling resistance genes, which resulted in effective stem rust resistance present in many wheat cultivars [7-10]. The partial resistance of $\mathrm{Sr} 2$ has remained effective for almost a century in all wheat growing areas of the world, and is also effective against Ug99 and its derivatives. However, to be economically effective, $\mathrm{Sr} 2$ must be combined with seedling resistance genes [11]. Consequently, the $\mathrm{Sr} 2$ gene will continue to form an important component of resistance gene combinations required to control stem rust epidemics.

The resistance conferred by $\mathrm{Sr} 2$ is characterized by a nonhypersensitive, partial resistance response, with varying effectiveness under field conditions. $\mathrm{Sr} 2$ is one of the few race non-specific, adult plant, resistance (APR) genes currently used to provide protection against stem rust in wheat. $\mathrm{Sr} 2$ stem rust resistance displays a dosage dependent resistance phenotype ("partial hemizygous effective" [6]), and is linked to pseudo-black chaff ( $\mathrm{PBC}$ ), a phenotypic trait that causes varying degrees of dark pigmentation on the stem internodes and glumes [8]. In certain backgrounds, $\mathrm{Sr} 2$ is also associated with race specific seedling resistance to leaf rust caused by $P$. triticina, due to the action of two complementary resistance genes, $L r 27$, which is linked to $S r 2$ [12] and the $L r 31$ gene on chromosome $4 \mathrm{~B}[8,13]$. The basis of this complementary effect is unknown. We have demonstrated that a gene for resistance to wheat powdery mildew, Blumeria graminis f. sp. triticae (Bgt), also maps to the $S r 2$ locus, but whether this resistance is race specific is unknown at this stage.

As a first step towards positional cloning of the gene, we previously mapped $\mathrm{Sr} 2$ on the short arm of chromosome $3 \mathrm{~B}$, constructed a high resolution map of the region [14], and were unable to break the linkage between $\mathrm{Sr} 2, \mathrm{Lr} 27$, powdery mildew resistance and the phenotypic marker, $\mathrm{PBC}$ [12]. In the present paper, we produce a physical map of the $\mathrm{Sr} 2$ region from Hope 3B, determine its DNA sequence and compare the haplotypes and gene content of the Sr2 locus in Hope and Chinese Spring wheats. This analysis has revealed a major presence-absence polymorphism in tetraploid and hexaploid wheat for a cluster of ten germin-like protein genes.

\section{Methods}

\section{Plant populations and phenotyping}

The generation of the high resolution mapping family between Chinese Spring and the chromosome 3B substitution line Chinese Spring (Hope3B) and the stem and leaf rust rust phenotyping has been described previously [12,14]. Seeds of emmer (Triticum turgidum var. dicoccum) accessions including cv Yaroslav and of Triticum aestivum cv Marquis and cv Hope were obtained from the Australian Winter Cereal Collection, Tamworth. The Chinese Spring 3BS deletion stock (3BS-8) was obtained from Wheat Genetic and Genomic Resource Center, Kansas State University, USA. The CAP lines were part of the US Wheat Coordinated Agricultural Project (CAP) and kindly provided by Gina Brown-Guedira USDA.

\section{Construction of the 3B-specific BAC library from cv. Hope} The BAC library from chromosome $3 \mathrm{~B}$ of $\mathrm{cv}$. Hope consisted of two sub-libraries designated TaaHop3BFhA and TaaHop3BFhB, respectively. Both sub-libraries were prepared from the DNA of chromosome 3B purified by flowcytometric sorting [15,16] (Additional file 1: Figure S1). Purified genomic DNA was partially digested with HindIII and cloned into the pIndigoBAC-5 vector (Epicentre, Madison, USA). The TaaHop3BFhA sub library was constructed from a limited number of chromosomes $\left(10^{6}\right.$, corresponding to $\sim 1.8 \mu \mathrm{g}$ DNA) as described in Šafár et al. [17], with some modifications. The smaller amount of DNA was compensated by lower than normal stringency size selection, including just one size-selection step and usage of DNA fractions of a relatively smaller size (55$80 \mathrm{~kb}$ and $80-115 \mathrm{~kb})$. This resulted in a BAC library consisting of 92,160 clones, with an average insert size of $78 \mathrm{~kb}$. This sub-library represented $\sim 6$-fold coverage of chromosome 3B. The TaaHop3BFhB sub library was constructed from $2 \times 10^{6}$ chromosomes $(\sim 3.6 \mu \mathrm{g}$ DNA) by applying two size-selection steps as described in Šimková et al. [18]. The higher amount of DNA allowed efficient cloning of larger DNA fragments (145-220 kb), resulting in a library of 43,776 BAC clones with mean insert size of $160 \mathrm{~kb}$, which also represented $\sim 6$-fold coverage of chromosome 3B. Screening of the library was done using

${ }^{32} \mathrm{P}$ labeled DNA probe using standard protocols.

Construction of a non-gridded BAC library from cv. Hope A second BAC library designated Tae-B-Hope-ng was constructed from cv Hope genomic DNA without 
chromosome sorting, at the Centre National de Resources Génomiques Végétales (CNRGV)- INRA, France. It was produced using a non-gridded BAC library construction protocol based on Isidore et al. [19] with the following modifications: (1) growth of pooled BAC clones in liquid LB medium; (2) BAC pools DNA amplification by whole genome Genomiphi.v2 phi29 enzyme kit (GE Healthcare) instead of DNA extraction; (3) use of secondary pooling steps in order to identify positive clone coordinates with less screening effort after clone picking. High molecular weight (HMW) DNA was prepared from $20 \mathrm{~g}$ of leaf material from cv. Hope. Embedded HMW DNA was partially digested with HindIII (Sigma-Aldrich, St-Louis, Missouri), size selected, eluted and ligated into pIndigoBAC-5 HindIII-Cloning Ready vector (Epicentre Biotechnologies, Madison, Wisconsin). Two successive HMW DNA extractions and three independent sizing steps led to production of 336,670 BAC clones (101 kb average insert size) representing a total $\sim 2$-fold coverage of genome. BAC clones were divided into 268 pools before overnight growth and DNA amplification. Pools were screened using specific PCR markers previously developed from clones in the $3 \mathrm{~B}$ sorted library. The primer sequences for the probe PCR fragments and PCR markers are summarized in Additional file 2: Table S1.

\section{BAC sequencing and sequence assembly}

BAC clones from the $\mathrm{Sr} 2$ locus of Hope were isolated using probes from the previously characterised $3 \mathrm{~B}$ locus of Chinese Spring and were sequenced by a BAC-byBAC shotgun method at $10 \times$ coverage using Applied Biosystems capillary sequencing. Base calling, quality trimming and assembly of the raw sequence reads into contigs were done using the PHRED/PHRAP/CONSED package [20,21] and GAP4 [22] from the Staden package was used for data integration and sequence finishing. The BACs isolated from the non-enriched Hope genomic DNA library were sequenced using Roche 454 sequencing platform. A hybrid assembly of the sequence from 454 and Sanger sequencing was done using Newbler v. 2.3. Additional gap closure was performed on the assembled scaffold sequences by sequencing pooled BAC DNA and an $8 \mathrm{~kb}$ paired end library using Roche 454 sequencing platform. Scaffolds were also assembled using Sequencher v. 5.2. Annotated sequence of $\mathrm{Sr} 2$ region in Hope has been deposited in GenBank (Acc no. KP244323).

\section{Gene annotation: gene prediction}

Genes were annotated using the gene prediction software packages FGENESH (www.softberry.com), AUGUSTUS (http://bioinf.uni-greifswald.de/augustus/) and GENSCAN (http://genes.mit.edu/GENSCAN.html). Gene calls were also made using CLC Genomics workbench v, 7.04. The predicted gene sequences were used for BLASTX and BLASTP analysis against protein databases (NCBI protein and Swiss-prot databases) to identify candidate genes and determine whether they were full length. Intron-exon structure of predicted genes was refined by BLAST comparisons of the predicted gene sequences with the Expressed Sequence Tag (EST) database at NCBI (http://www.ncbi. nlm.nih.gov/dbEST/).

\section{Gene annotation: RNA-seq}

Further expressed sequences in the $\mathrm{Sr} 2$ region were identified by aligning RNA-seq reads from leaves of cv Hope with the $\mathrm{Sr} 2$ genomic sequence. Because of the association of mildew and rust resistance at the $S r 2$ locus, this RNA was isolated from plants that were inoculated with mildew at four weeks after sowing by applying spores of a glasshouse isolate of Bgt to the abaxial surface of the leaves with a dry paint brush, followed by application of a fine spray of water. Plants were maintained under a shade curtain in the glasshouse at $23^{\circ} \mathrm{C}$, in tubs of shallow water to increase humidity, and leaves were sampled at 15 hours after inoculation, and at five days after inoculation. Total RNA was isolated using a Qiagen RNA-Easy Plant Minikit, and RNA was DNase-treated on the column using the Qiagen protocol. A pooled sample containing 50\% each of DNase-treated RNA isolated from leaves collected at 15 hours and five days after inoculation was sequenced by the Australian Genome Research Facility. RNA-seq was quality trimmed and aligned to the Hope $\mathrm{Sr} 2$ genomic sequence using CLC-Genomics Workbench. Expressed regions of the genomic sequence, for which RNA-seq reads aligned at $100 \%$ identity, were annotated by BLASTN comparison with DNA sequence databases.

\section{Mapping}

Gene sequences identified in the $\mathrm{Sr} 2$ region of Hope and CS were mapped as PCR markers (Additional file 2: Table S1) using the high resolution mapping family described previously [12,14]. The specificity of PCR markers to chromosome $3 \mathrm{~B}$ was confirmed using the DNA of the Chinese Spring 3BS-8 deletion line. PCRs were performed in a volume of $20 \mu \mathrm{l}$ with $10 \mathrm{mM}$ of each primer, $0.2 \mathrm{mM}$ dNTPs, $1.5 \mathrm{mM} \mathrm{MgCl}_{2}, 1.0$ units GoTaq DNA polymerase (Promega) and 100-200 ng of template DNA. The annealing temperature used for PCR was generally $3-4^{\circ} \mathrm{C}$ below the $\mathrm{T}_{\mathrm{m}}$ of the primers used.

\section{Results}

A BAC contig for the Sr2 region in the stem rust resistant cv Hope

Although the sequence information from the non-Sr2 carrying wheat Chinese Spring (henceforth CS) wheat was useful initially [23,24], the characterisation of the locus required BAC clones from the $\mathrm{Sr} 2$ carrying region of Hope 
wheat. A BAC library was prepared from flow sorted chromosome $3 \mathrm{~B}$ of Hope and screened with low copy markers derived from the ends of CS BAC clones. A total of 11 BACs were identified that formed six contigs (Figure 1). Efforts to isolate additional BAC clones from this library, and to close the gaps between the contigs were unsuccessful. To complete the physical map, an additional whole genome BAC library was developed from Hope, and screened with markers flanking the gaps. The positions of the seven newly selected BAC clones were confirmed on the basis of sequence identity with overlapping regions from the BACs derived from the $3 \mathrm{~B}$ chromosome-sorted library and also genetic mapping of markers which were derived from these new clones. In total, the 18 BAC clones formed a single contig of $968 \mathrm{~kb}$, and included the distal and proximal markers $R K O \_1$ and $D O X \_1$ that recombined with $\mathrm{Sr} 2$. The same interval in CS was $567 \mathrm{~kb}$ long [24] indicating that the two haplotypes were substantially divergent and included deletion/insertion events. The DNA sequence of the $968 \mathrm{~kb} \mathrm{Sr} 2$ region (Genbank KP244323) was determined by sequencing all $18 \mathrm{BAC}$ clones.

\section{Gene annotation of the Hope Sr2 genomic region sequence and comparison to CS}

Gene annotation of the $968 \mathrm{~kb} \mathrm{Sr} 2$ region was done using gene prediction software and by comparison with the published CS genomic sequence covering the region (Genbank accession FN645450). In addition, sequences from the Hope $\mathrm{Sr} 2$ region that were expressed in pathogen challenged leaves of Hope were identified by alignment of RNA-seq data with the Sr2 region DNA sequence. Table 1 lists sequentially all identified genes and their sequence coordinates in the $\mathrm{Sr} 2$ genomic region of Hope compared to the corresponding region of the previously annotated CS sequence. The annotation identified 34 genes and gene fragments from the Hope $\mathrm{Sr} 2$ cosegregating region between the RKO_1 and DOX_1 flanking markers whereas only 17 genes and gene fragments were identified in the corresponding region of CS.

Based on the level of sequence identity between CS and Hope, the Sr 2 locus was divided into two sections (Figures 1 and 2). The proximal section (section 1, $45 \mathrm{~kb}$ to $360 \mathrm{~kb}$ ) of the Hope $\mathrm{Sr} 2$ locus sequence showed high similarity with the corresponding region from CS. Eight genes were annotated in section 1 of both Hope and CS, with 2 additional genes present in CS (Table 1) [24]. The length and gene content of this sub-region were closely comparable between CS and Hope, except for a segment of approximately $40 \mathrm{~kb}$ in CS, containing a Flowering Locus $\mathrm{T}$ - like gene and EMB_2, which were missing in Hope (Table 1). Most of the shared genes in section 1 contained several DNA sequence polymorphisms between the CS and Hope, and their

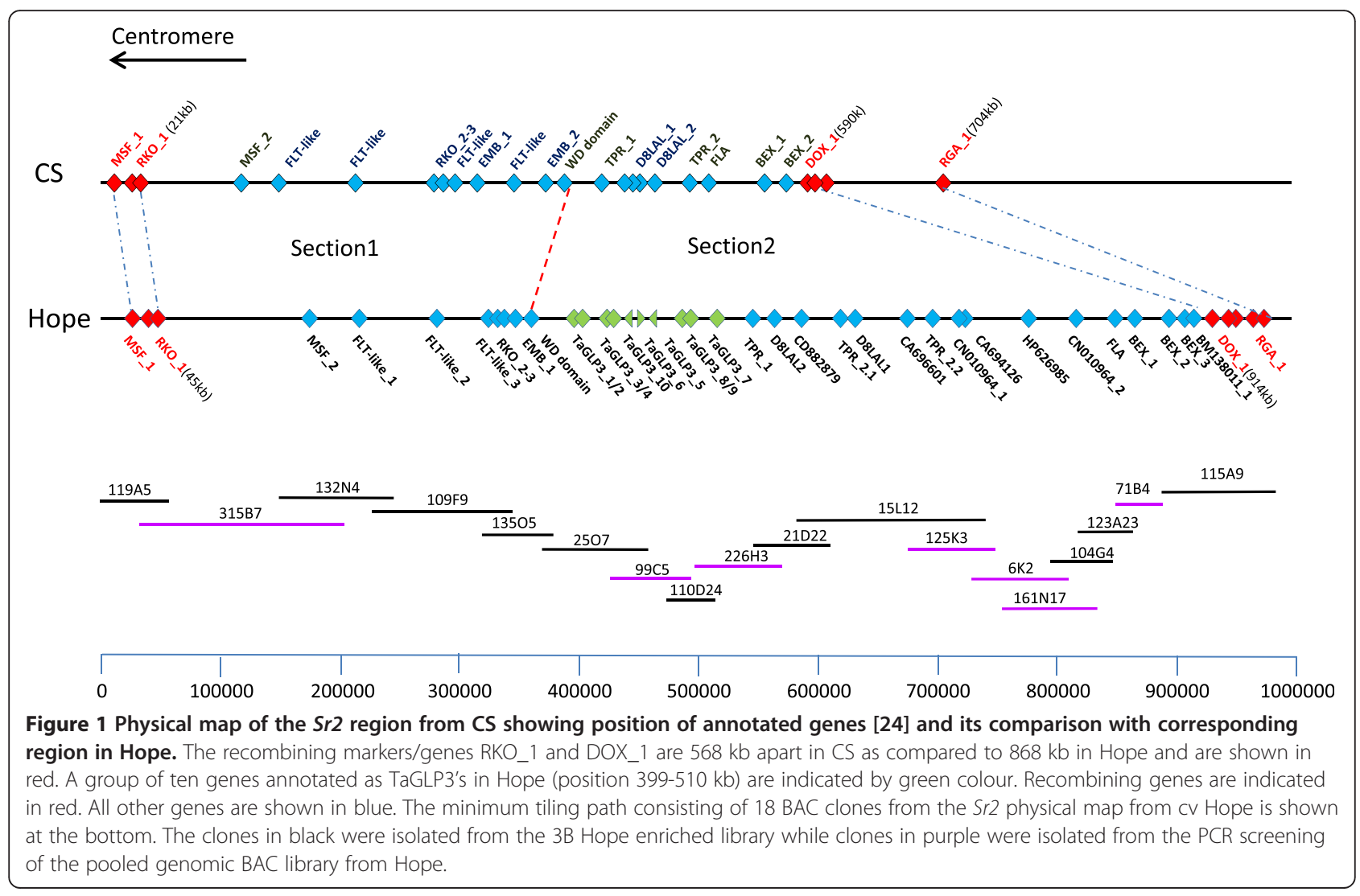


Table 1 Gene annotation of Hope Sr2 region and comparison with the corresponding region in CS

\begin{tabular}{|c|c|c|c|c|c|c|}
\hline No. & Name & Annotation & $\begin{array}{l}\text { Hope gene } \\
\text { start }\end{array}$ & $\begin{array}{l}\text { Hope gene } \\
\text { end }\end{array}$ & CS gene id & $\begin{array}{l}\text { CS gene } \\
\text { pos }\end{array}$ \\
\hline 1 & $\mathrm{MSF}_{-} 1^{\text {\$ }}$ & Male sterility factor & 29132 & 35097 & ctg0011b.00010.1 & 8024 \\
\hline 2 & $E P_{-} 1^{\$}$ & Hypothetical protein & 39298 & 41832 & ctg0011b.00020.1 & 16001 \\
\hline 3 & $\mathrm{RKO}_{-} 1^{\$}$ & Receptor kinase & 45570 & 48036 & ctg0011b.00030.1 & 21207 \\
\hline 4 & MSF_2 $2^{\$}$ & Male sterility factor & 174463 & 180047 & ctg0011b.00040.1 & 130246 \\
\hline 5 & Flowering Locus T-like_1 & Flowering Locus T-like protein & 207129 & 208229 & ctg0011b.00050.1 & $154860^{*}$ \\
\hline 6 & Flowering Locus T-like_2 & Flowering Locus T-like protein & 274176 & 275721 & ctg0011b.00060.1 & 218850 \\
\hline 7 & Flowering Locus T-like_3 & Flowering Locus T-like protein & 322283 & 323263 & ctg0011b.00070.1 & 281996 \\
\hline 8 & RKO_2 & receptor kinase & 329447 & 331621 & ctg0011b.00080.1 & 293102 \\
\hline 9 & RKO_3 & receptor kinase & 332015 & 335105 & ctg0011b.00090.1 & 295683 \\
\hline 10 & EMB_1 & PPR repeat domain containing protein & 339212 & 341395 & ctg0011b.000100.1 & 307937 \\
\hline 11 & Flowering Locus T-like & Flowering Locus T-like protein & - & - & ctg0011b.000110.1 & 351119 \\
\hline 12 & $E M B \_2^{\#}$ & PPR repeat domain containing protein & - & - & ctg0011b.000120.1 & 379263 \\
\hline 13 & WD domain* & similar to WD domain, G-beta repeat & 349395 & 355055 & ctg0011b.000130.1 & 385794 \\
\hline 14 & GLP_1 & Germin-like protein & 398118 & 398929 & & - \\
\hline 15 & GLP_2 & Germin-like protein & 399614 & 400424 & & - \\
\hline 16 & GLP_3 & Germin-like protein & 423764 & 424562 & & - \\
\hline 17 & GLP_4 & Germin-like protein & 425172 & 425984 & & - \\
\hline 18 & GLP_10* & Germin-like protein & 444653 & 445216 & & \\
\hline 19 & GLP_6* & Germin-like protein & 455726 & 456520 & & - \\
\hline 20 & GLP_5* & Germin-like protein & 463024 & 463811 & & - \\
\hline 21 & GLP_8 & Germin-like protein & 474211 & 475020 & & - \\
\hline 22 & GLP_9 & Germin-like protein & 475777 & 476588 & & - \\
\hline 23 & GLP_7 & Germin-like protein & 508822 & 509633 & & - \\
\hline 24 & TPR1 & Tetratricopeptide repeat domain containing protein & 546645 & 549809 & ctg0011b.000140.1 & 435705 \\
\hline 25 & D8LAL2 & Hypothetical protein & 562871 & 565156 & ctg0011b.000160.1 & 447301 \\
\hline 26 & CD882879 & Hypothetical protein & 587682 & 589820 & & 464713 \\
\hline 27 & TPR2* & Tetratricopeptide repeat domain containing protein & 613921 & 615236 & ctg0011b.000170.1 & 498370 \\
\hline 28 & D8LAL1 & Hypothetical protein & 625926 & 626996 & ctg0011b.000150.1 & 443924 \\
\hline 29 & CA696601 & Hypothetical protein & 670987 & 671361 & & \\
\hline 30 & TPR2* & Tetratricopeptide repeat domain containing protein & 692673 & 695113 & ctg0011b.000170.1 & 498370 \\
\hline 31 & CN010964 & Hypothetical protein & 710337 & 711484 & & $574223^{*}$ \\
\hline 32 & CA694126 & No annotation & 712343 & 712774 & & $507295^{*}$ \\
\hline 33 & HP626985 & Hypothetical protein & 776063 & 776392 & & $507441^{*}$ \\
\hline 34 & CN010964 & Hypothetical protein & 809317 & 810476 & & $574223^{*}$ \\
\hline 35 & FLA30 & fasciclin-like arabinogalactan precursor & 840622 & 841206 & ctg0011b.000180.1 & 510269 \\
\hline 36 & BEX_1 & beta-expansin 1a precursor & 846394 & 847826 & ctg0011b.000190.1 & 561427 \\
\hline 37 & BEX_2 & beta-expansin 1a precursor & 854813 & 856068 & ctg0011b.000200.1 & 570188 \\
\hline 38 & BEX_3 & beta-expansin 1a precursor & 892334 & 893409 & & \\
\hline 39 & BM138011_1 & BTB-domain containing protein & 909112 & 909465 & & \\
\hline 40 & DOX_1 $1^{\$}$ & disulfide oxidoreductase & 914790 & 916571 & $\operatorname{ctg} 0011 b .000210 .1$ & 590774 \\
\hline 41 & CA681101 & Hypothetical protein & 923311 & 923709 & & 599356 \\
\hline 42 & BM138011_2 & BTB-domain containing protein & 926622 & 926983 & & 602889 \\
\hline 43 & BTB-domain containing protein $\$$ & & 957404 & 959539 & & $109661^{*}$ \\
\hline 44 & RGA_1 $1^{\$ *}$ & similar to disease resistance RPM1-like protein & 960894 & 966749 & $\operatorname{ctg} 0011 b .000220 .1$ & 704997 \\
\hline
\end{tabular}

${ }^{\$}$ Recombining genes; *partial genes/pseudogenes; Not present in Hope. 
predicted protein products differed by one or more amino acid polymorphisms.

In section two (360 kb to $915 \mathrm{~kb}$; Figures 1 and 2), distal to the shared WD-domain pseudogene, the Hope and CS regions differed markedly. In this region, 26 putative genes were annotated in Hope, whereas only seven genes or gene fragments were annotated in CS. (Table 1). Small regions of high similarity between Hope and CS were evident at 560-590 kb and at 900-968 kb (Figure 1) but apart from these islands of similarity, the two DNA sequences diverged radically. Most notably, an insertion of approximately $100 \mathrm{~kb}$ containing ten genes annotated as germin-like proteins (GLPs) was present in Hope, positioned between CS gene ids ctg0011b.000130.1 and 140.1 (Table 1). Despite the lack of overall sequence similarity across the distal part of the locus, other genes that were annotated between WD-domain and DOX_1 were present in both haplotypes (Table 1, Figure 1). This section of the $\mathrm{Sr} 2$ locus contained several genes of unknown function (hypothetical proteins, Table 1) that were identified by alignment of the genomic sequence with RNA seq data. These expressed sequences were not annotated as putative genes in the published CS sequence (FN645450), and are listed with the accession number of the most similar GenBank EST in Table 1. For CA696601, CN010964, CA694126, HP626985, CN010964 and BM138011, the sequences in Hope were predicted to encode small proteins (e.g. 84 amino acids for CN010964), but in CS the putative genes were truncated. Overall, the DNA regions that encode these predicted proteins showed 80 to $92 \%$ DNA sequence identity between the $\mathrm{Sr} 2$ haplotypes. CD882879 encoded a predicted protein of 374 amino acids in Hope and 378 amino acids in CS. Re-sequencing of the gene from CS revealed an error in the deposited FN645450 CS sequence, in which insertion of an extra nucleotide disrupted the open reading frame, resulting in the gene not being annotated in the original CS genomic sequence [24]. The protein coding regions of the CD882879 genes from Hope and CS shared 92\% DNA identity, predicting proteins with $90 \%$ amino acid identity.

Hypothetical genes D8LAL1 and D8LAL2 were positioned $4 \mathrm{~kb}$ from each other in the CS genomic sequence. In contrast, the relative position of these genes was reversed and $60 \mathrm{~kb}$ apart in Hope, indicating that inversion and insertion events occurred at this position between the two haplotypes. Predicted genes encoding a fasciclin-like arabinogalactan precursor (FLA; gene id ctg0011b.000180.1), two beta-expansin 1a precursor proteins (BEX_1 and BEX_2; gene ids ctg0011b.000190.1, ctg0011b.000200.1), and a putative disulfide oxidoreductase (DOX_1; gene id ctg0011b.000210.1) formed the distal end of the Sr2 locus in both Hope and CS. All these genes were also present in the corresponding Hope region, as well as an additional copy of the truncated tetratricopeptide repeat domain containing protein, TPR_2 and a beta-expansin precursor, annotated as BEX_3 (Table 1).

\section{Mapping Sr2 with respect to newly derived DNA markers}

To establish the region that co-segregated with $\mathrm{Sr} 2$, PCR markers developed from polymorphic regions of the Hope and CS sequences were mapped in the high resolution mapping family developed by Kota et al. [14]. At the proximal end of the $S r 2$ region, the marker from the MSF_1 gene (CS gene id ctg0011b.00010.1) was separated from $\mathrm{Sr} 2$ in two recombinants, while the marker from the RKO_1 gene (CS gene id ctg0011b.00030.1)

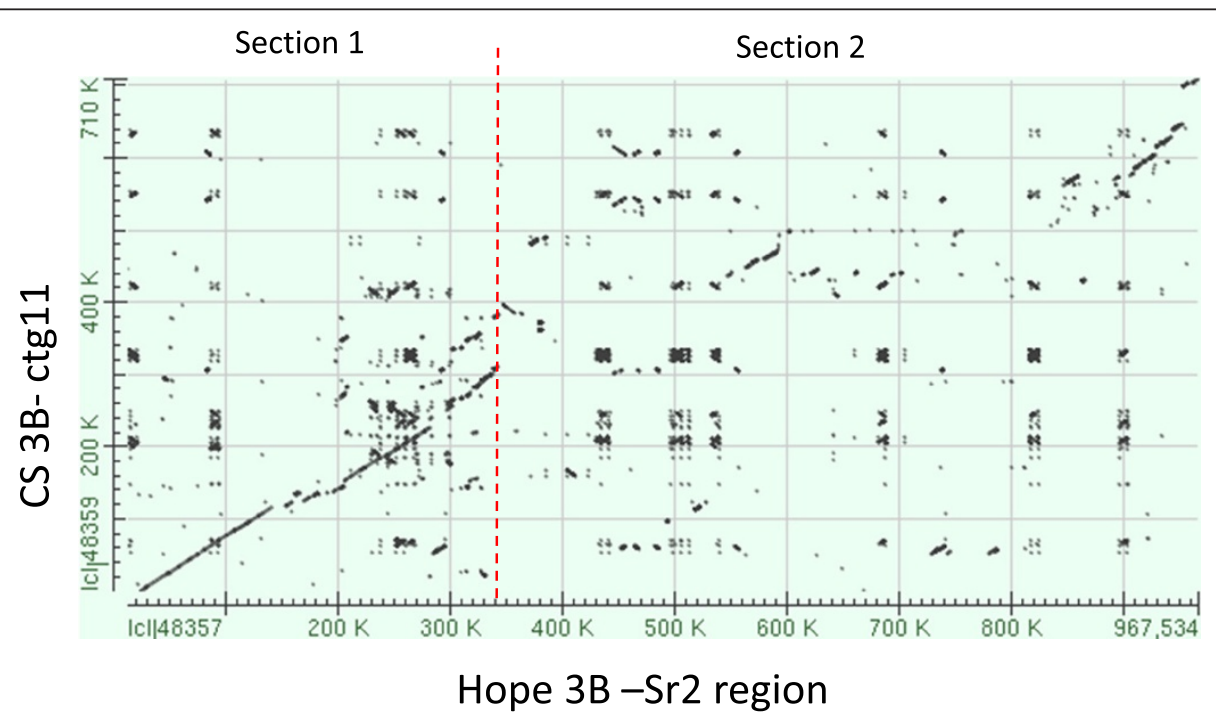

Figure 2 Dot-matrix plot of the Hope (3B) Sr2 region with the corresponding region on CS (3B; part of ctg11, GenBank FN645450). Section 1 denotes region between 45-360 kb, section two includes 360-915 kb region. 
was separated by one recombinant. At the distal end, marker RGA_1, derived from a nucleotide bindingleucine rich repeat gene (NB-LRR), was separated from $\mathrm{Sr} 2$ in two recombinants, while DOX_1 (CS gene id ctg0011b.000210.1) was separated in a single recombinant. Markers developed from genes between RKO_1 and DOX_1 co-segregated with Sr2. The genes shared between Hope and CS all encoded proteins with one or more polymorphisms between the two haplotypes, and several genes, including the GLPs were specific to Hope. Thus, sequence comparisons alone were unable to pinpoint a specific candidate for $\mathrm{Sr} 2$.

\section{Sr2-linked GLPs}

The GLP genes co-segregating with $\mathrm{Sr} 2$ were of particular interest because of the reported association of GLPs with plant defence ([25] and references therein). Following the convention used for naming GLPs on chromosome 8 of rice [26], the ten GLPs from the $S r 2$ locus were named TaGLP3_1 to TaGLP3_10 (Triticum aestivum Germin-like proteins from chromosome 3 , numbered from proximal to distal). TaGLP3_5, 6 and 10 were pseudogenes because they encoded truncated proteins compared to the other GLPs. Of the remaining seven apparently full-length genes, six, (TaGLP3_ 1/2, -3/4 and - 8/9) were organised as divergently-transcribed pairs, each separated by 610 675 bps between predicted ATG translation start codons, presumably constituting a short, shared promoter (Figure 3). Only TaGLP3_7 was present as a single gene. Sequence comparison showed that the $\mathrm{Sr} 2$ locus TaGLP3s could be organised into 2 sequence groups (Table 2 and Figure 4). One group consisted of GLPs 1, 3, 6, 8 and 10 (TaGLP3_1 group), while GLPs 2, 4, 5, 7 and 9 (TaGLP3_2 group) formed the second category. The sequence identity between members within a group ranged between $93-98 \%$ while the identity between the GLPs in different groups was 77-82\%. For divergently transcribed genes, the gene pair consists of one member of each group. Comparisons of the derived amino acid sequences of the wheat TaGLP3s with sequences from wheat, barley and rice showed that the TaGLP3s were most closely related to a previously undescribed, single, divergently transcribed pair of barley GLPs at a putatively orthologous locus on chromosome 3H (http://plants.ensembl.org/Hordeum_vulgare/Info/ Index). Less similar sequences were also present in other cereals, including rice and Brachypodium, although not necessarily at syntenic genomic locations. The TaGLP3s and the orthologous barley GLP gene pair products shared more than $90 \%$ amino acid identity with each other, and shared 80 to $84 \%$ identity with the next most similar sequences in barley, the Ger4 sub-family, and with the most similar sequences in rice, a group of Ger4 sub-family OsGLP8s on chromosome 8 (Figure 4).

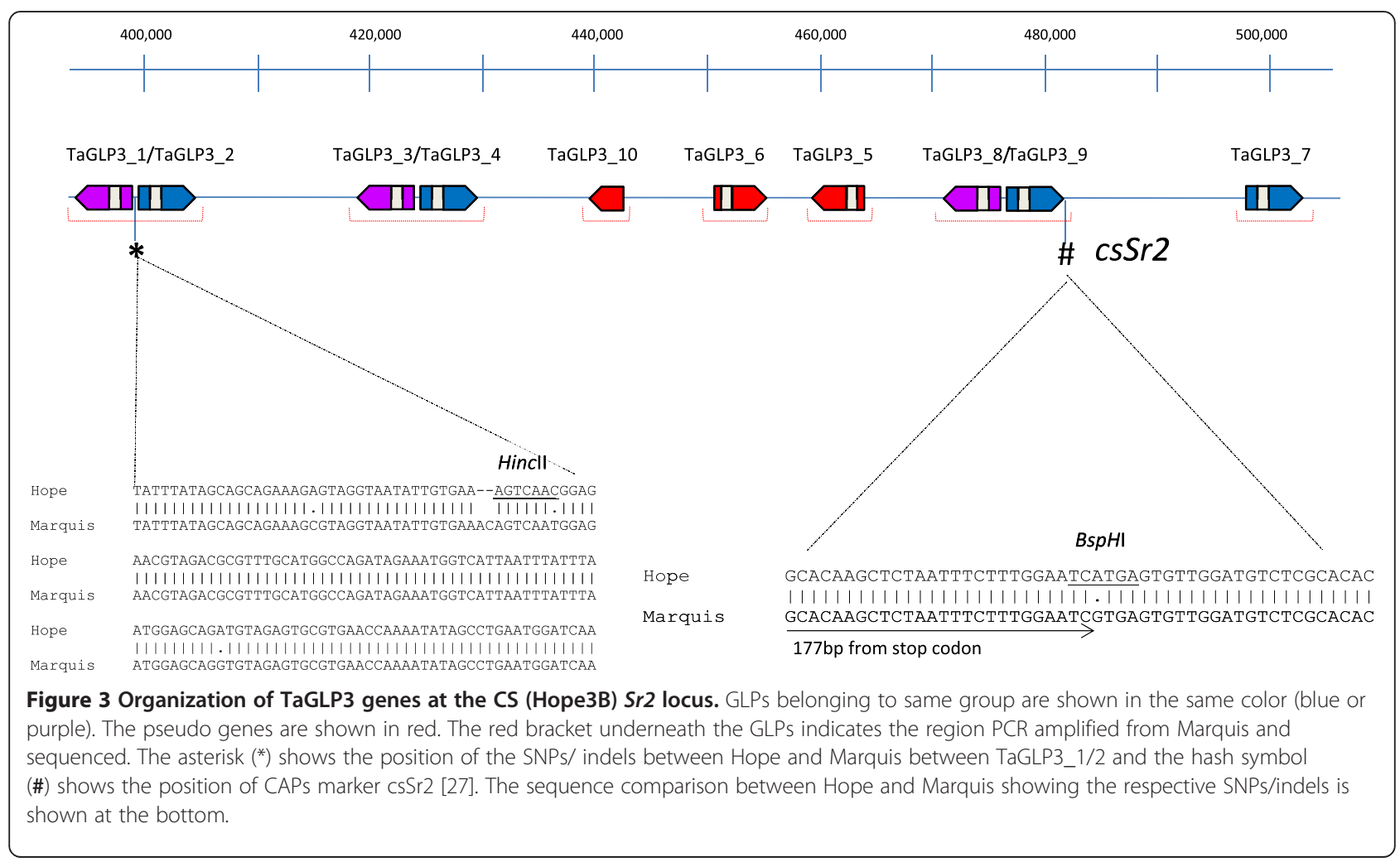


Table 2 Comparison of Hope Sr2 locus TaGLP3 predicted protein sequences

\begin{tabular}{lllllllll}
\hline & & $\mathbf{1}$ & $\mathbf{2}$ & $\mathbf{3}$ & $\mathbf{4}$ & $\mathbf{5}$ & $\mathbf{6}$ & $\mathbf{7}$ \\
\hline 1. & TaGLP3_1 & 100 & & & & & & \\
2. & TaGLP3_2 & 86 & 100 & & & & & \\
3. & TaGLP3_3 & 97 & 88 & 100 & & & & \\
4. & TaGLP3_4 & 78 & 89 & 79 & 100 & & & \\
5. & TaGLP3_7 & 85 & 96 & 87 & 88 & 100 & & \\
6. & TaGLP3_8 & 96 & 86 & 96 & 77 & 85 & 100 & \\
7. & TaGLP3_9 & 85 & 96 & 87 & 87 & 97 & 85 & 100 \\
\hline
\end{tabular}

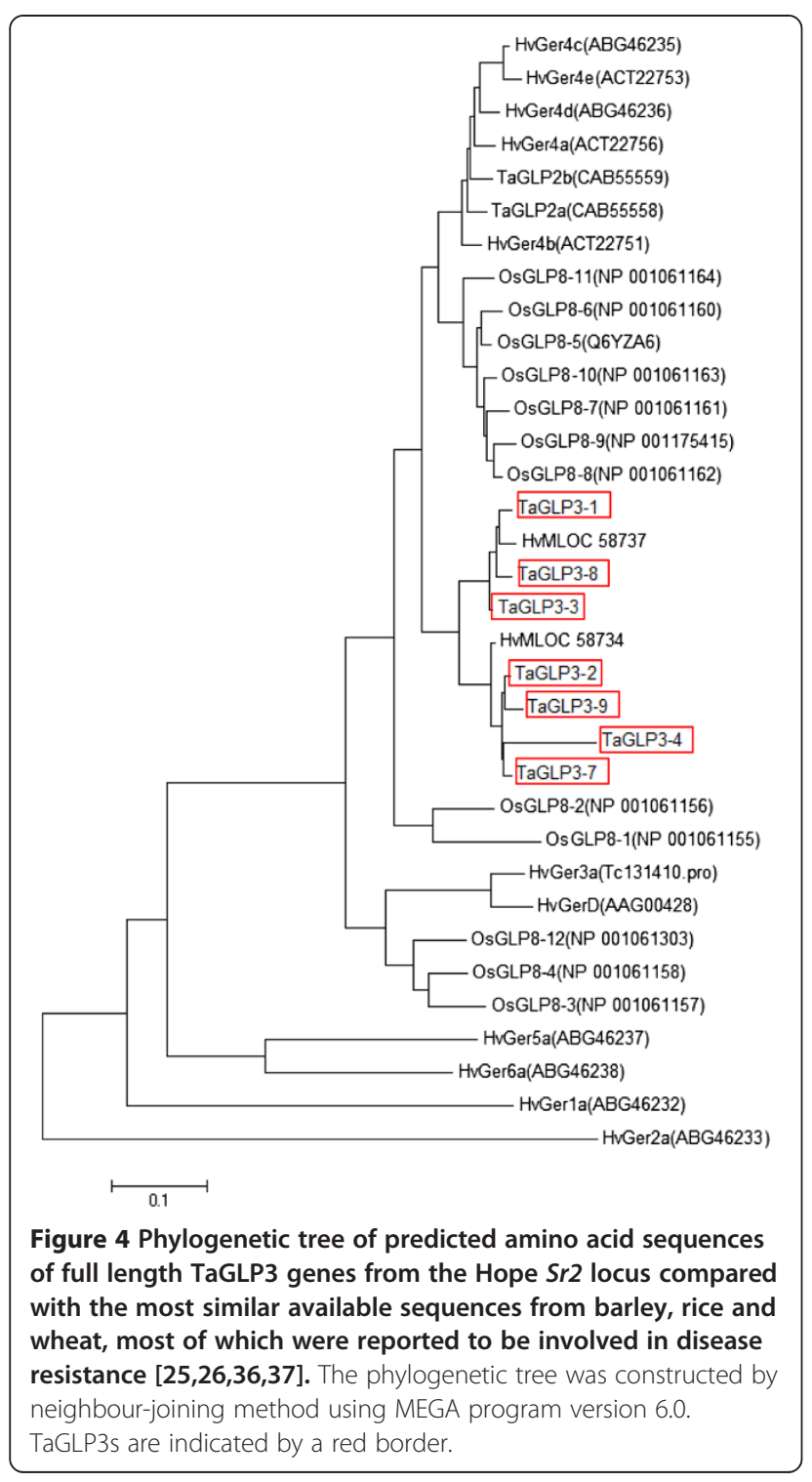

\section{Amplification of TaGLP3s from hexaploid and tetraploid wheat}

To further investigate the TaGLP3 presence/absence polymorphism in other wheat genotypes, we designed PCR primers based on Hope coding and non-coding sequences for all the TaGLP3s (including approximately $1 \mathrm{~kb}$ flanking sequence) to determine if the large insertion carrying these GLPs was present in other wheats. All GLPs amplified from genomic DNA of the wheat cultivar Marquis (see Figure 3 for regions which were sequenced in Marquis), which was the original recipient of Sr2 from emmer, while none could be amplified from CS indicating that this polymorphism existed in hexaploid wheat before introgression of Sr2. Three SNPs and two nucleotide insertions were identified in the shared promoter of TaGLP3_ 1/2 between Hope and Marquis (Figure 3). Sequencing of the promoter region and predicted coding sequences of TaGLP3_1 and 3-2 from diverse germplasm including CAP10, CAP12, CAP13, CAP16, CAP30, CAP31 and CAP32 revealed only the Hope or Marquis haplotypes (Table 3). One of these polymorphisms resulted in loss of a HincII restriction site in the Marquis sequence and was used to develop a CAPS marker (GLP-1/2 CAPs). A second SNP occurred 3' of TaGLP3 -9 and was previously developed as a diagnostic PCR marker for $\mathrm{Sr} 2$, csSr2 [27]. PCR was used to assess the presence of the TaGLP3s in a range of hexaploid and tetraploid wheat genotypes (Table 3). Based on the PCR screening, four haplotypes were identified: 1. Both PCR products did not amplify (null), 2. Both PCR products carried the Marquis alleles (MM), 3. Both PCR products carried the Hope alleles (HH), 4. TaGLP3_1/ 2 CAPs generated the Hope allele, while csSr 2 amplified the Marquis allele (HM). The tetraploid durums and nine out of the 11 emmers were null for both markers. Yaroslav and AUS 3511 emmer contained the Hope allele for both markers (HH), while a second emmer (AUS19385) carried the Hope allele at TaGLP3_ 1/2 and the Marquis allele for csSr2 (HM). In hexaploid wheat, all four haplotypes were present (Table 3). The csSr2 marker was diagnostic for the presence of $\mathrm{Sr} 2$ in a wide range of wheat genotypes [27], however the TaGLP3_1/2 CAPs marker detected the Hope allele in several wheats that lacked $\mathrm{Sr} 2$ confirming that csSr2 is the more useful marker (Table 3). Most significantly, no differences were detected between Hope and Marquis in the coding regions of the GLP genes.

\section{Discussion}

\section{$\mathrm{Sr} 2$ is not related to NB-LRR resistance genes or APR genes $L r 34$ and $Y r 36$}

In this study we have determined the sequence of a region of the wheat chromosome carrying the $\mathrm{Sr} 2$ adult plant stem rust resistance gene from cv Hope, and compared DNA sequence and gene content with the non$\mathrm{Sr} 2$ cultivar Chinese Spring that was used as the rust 
Table 3 Marker survey of TaGLP3 CAPs markers in tetraploid and hexaploid wheats

\begin{tabular}{|c|c|c|c|}
\hline Genotype & Sr2 & TaGLP3_1/2 CAPs & $\operatorname{csSr2}$ \\
\hline Langdon & - & - & - \\
\hline Bansi & - & - & - \\
\hline Glossy Huguenot & - & - & - \\
\hline Emmer (AUS 3511) & $?$ & $\mathrm{H}$ & $\mathrm{H}$ \\
\hline Emmer (AUS 3728) & $?$ & - & - \\
\hline Emmer (AUS 3741) & $?$ & - & - \\
\hline Emmer (AUS 3743) & $?$ & - & - \\
\hline Emmer (AUS 3745) & $?$ & - & - \\
\hline Emmer (AUS 3748) & $?$ & - & - \\
\hline Emmer (AUS 10731) & $?$ & - & - \\
\hline Emmer (AUS 11436) & $?$ & - & - \\
\hline Emmer (AUS 15520) & $?$ & - & - \\
\hline Emmer (AUS 18175) & $?$ & - & - \\
\hline Emmer (AUS 19385) & $?$ & $\mathrm{H}$ & M \\
\hline Yaroslav Emmer (AUS 2789) & + & $\mathrm{H}$ & $\mathrm{H}$ \\
\hline Chinese Spring & - & - & - \\
\hline CS/Hope(3B) & + & $\mathrm{H}$ & $\mathrm{H}$ \\
\hline Marquis & - & M & M \\
\hline Thatcher & - & M & M \\
\hline CAP10 [Q36 (OR9900553)] & - & $\mathrm{H}$ & M \\
\hline CAP12 (Penawawa) & $?$ & $\mathrm{H}$ & $\mathrm{H}$ \\
\hline CAP13 (Finch) & - & $\mathrm{H}$ & M \\
\hline CAP16 (NY18/CC 40-1) & $?$ & M & M \\
\hline CAP30 (2174) & $?$ & $\mathrm{H}$ & M \\
\hline CAP31 (Weebill 1) & $?$ & $\mathrm{H}$ & M \\
\hline CAP32 (Jupateco 73S) & $?$ & $\mathrm{H}$ & M \\
\hline Aroona & - & - & - \\
\hline Arrino & - & - & - \\
\hline Turmbull & - & $\mathrm{H}$ & M \\
\hline Brookton & - & - & - \\
\hline Cadenza & & - & - \\
\hline Diamondbird & + & $\mathrm{H}$ & $\mathrm{H}$ \\
\hline Dollarbird & + & $\mathrm{H}$ & $\mathrm{H}$ \\
\hline Federation & - & - & - \\
\hline Pavon & + & $\mathrm{H}$ & $\mathrm{H}$ \\
\hline Sunstate & + & $\mathrm{H}$ & $\mathrm{H}$ \\
\hline Purplestraw & - & $\mathrm{H}$ & M \\
\hline Fultz & - & $\mathrm{H}$ & M \\
\hline
\end{tabular}

Note: $\mathrm{H}=$ Hope type, $\mathrm{M}=$ Marquis type, $-=$ Null,? = not known.

susceptible parent in a high resolution mapping of $\mathrm{Sr} 2$ $[12,14]$. There were no nucleotide binding site leucine rich-repeat (NB-LRR) genes, the most frequent class of resistance gene, that co-segregated with $\mathrm{Sr} 2$, which indicates that $\mathrm{Sr} 2$ is not a member of this class. Further, no sequences related to other cloned APR genes such as Lr34 or Yr36 occured in the region [28,29]. There were many polymorphisms, including large indels between the two haplotypes, preventing identification of $\mathrm{Sr} 2$ from sequence data alone.

\section{Haplotype divergence and gene cloning}

The $\mathrm{Sr} 2$ region of Hope and CS diverged in gene content, including the presence in Hope, and absence in CS, of a cluster of ten GLP genes. Large insertion-deletion events have been reported at other loci in wheat and in other cereals. For example, physical mapping of the adult plant stripe rust resistance locus $\operatorname{Yr} 36$ [29] showed a $183 \mathrm{~kb}$ insertion in the resistant line RSL65 compared to the susceptible durum wheat Langdon. This region, carrying four genes including the $Y r 36$ resistance gene, originated from the wild species T. turgidum var. dicoccoides. Similarly, a deletion of $351 \mathrm{~kb}$ was reported in T. turgidum var. dicoccoides compared to Langdon in the region containing Tsn1, a gene that confers sensitivity to the toxin ToxA in $\tan$ spot disease of wheat $[30,31]$ In rice, large sequence variation between a wild donor species and a recurrent parent was reported for the yield-improving QTL, q-GY2 [32]. In this study, we report major haplotype divergence within the hexaploid wheat species, indicating that large insertion/deletion events may be common, and not restricted to comparisons between inter-species haplotypes. Such major differences will impede rapid, map-based identification of target genes in specific wheat genotypes, even when high quality, reference genome sequence of CS becomes available. It is also likely that haplotype divergence, especially the large insertion/deletion of GLPs in the $\mathrm{Sr} 2$ region, resulted in the suppression of recombination and lack of genetic resolution of the target region. Consequently, a new mapping family was established by using Marquis, which carries the GLP gene cluster, as the susceptible parent. Initial results have indicated that in this family, recombination occurred within the region that previously co-segregated with $\mathrm{Sr} 2$. The characterisation of new recombinants is in progress.

\section{What is the possible evolutionary value of the presence} /absence GLP polymorphism on $3 \mathrm{~B}$ ?

It has been suggested that GLP functional diversity has arisen via sequential gene duplication events, followed by mutation, including in flanking regulatory regions, giving rise to diversity in temporal and spatial gene expression patterns [25]. Diverse wheats reflect four GLP haplotypes in the $\mathrm{Sr} 2$ region; $\mathrm{Sr} 2$ types with the Hope allele at TaGLP3_9 and TaGLP3_1/2, Marquis types with the Marquis allele at TaGLP3_9 and either the Marquis or Hope allele at TaGLP3_1/2, and CS types with no GLPs at the locus (Tables 2 and 3) [27]. The Hope 
haplotype with $\mathrm{Sr} 2$ and stem rust resistance has been selected by breeders. It is possible that there is an as yet undefined selection acting for or against the Marquis $($ GLP +) and CS (GLP -) haplotypes in different geographic regions, which may account for the wide spread occurrence of the chromosome 3B presence/absence polymorphism in Sr2- wheat genotypes. This is reminiscent of the presence/ absence polymorphism for the resistance gene RPM1 in Arabidopsis thaliana field populations that has been interpreted to result from balancing selection [33].

\section{Germin-like proteins}

The GLP genes at the $S r 2$ locus are of interest because of the reported association of this category of genes with plant defence responses. GLPs are small ( $\sim 220$ amino acid residues), secreted, functionally and taxonomically diverse cupin domain-containing proteins, two of which are reported to produce hydrogen peroxide, a plant defence signal, while several other members of the protein family have been associated with other enzymatic functions [34]. Sequence analysis showed that TaGLP3s at the Sr2 locus were most similar to a pair of divergently-transcribed GLPs at a syntenic position on barley chromosome $3 \mathrm{H}$ (Figure 4). The TaGLP3s and this orthologous barley locus, which is distinct from GerD previously mapped on barley chromosome $3 \mathrm{H}$ [35], constitute a novel sub-family of GLPs which has not been studied previously, and as far as we are aware, the only sub-family transcribed divergently from short intergenic promoters. The next closest GLP sub-family relative of the $S r 2$ locus sub-family is the GER4 class of GLP proteins in wheat, barley and rice, members of which have all been functionally associated with fungal disease resistance (Figure 4) ([25] and references therein). Transient over-expression of HvGER4 or HvGER5, as well as transient silencing by RNA interference of HvGER3 or HvGER5 [36] protected barley epidermal cells from attack by powdery mildew. Transient expression of wheat orthologs of HvGER4, germin-gf-2.8, TaGLP2a and TaGLP2b (which have identity between $72-82 \%$ with TaGLP3s) in epidermal cells also reduced the penetration efficiency of the powdery mildew fungus Blumeria graminis f. sp. hordei in wheat [37]. No experiments involving over-expression of GLPs in stable transgenic wheat or barley that confirm a direct role of these genes in disease resistance have been reported. Manosalva et al. [26] identified a QTL for rice blast resistance containing a cluster of 12 GLPs on rice chromosome 8, consisting of both GER3 and GER4 sub-family GLPs. RNA interference studies in transgenic rice showed that as more OsGLP genes were suppressed, disease susceptibility of the plants increased. Of the 12 OsGLPs, the OsGLP8-4 member (ortho$\log$ of HvGER4) was most effective in providing resistance. The resistance conferred by this QTL was effective against the rice blast and sheath blight pathogens. Despite the sequence similarity between the TaGLP3 gene cluster at the $\mathrm{Sr} 2$ locus and GLPs from other cereals that are associated with disease resistance, our data show that the predicted amino acid sequences of the TaGLP3s are identical between the stem rust sensitive $\mathrm{cv}$ Marquis, and the resistant cv Hope. Future analysis will determine whether the sequence polymorphisms adjacent to TaGLP3_1,2 or 9 are associated with any differences in gene expression between Hope and Marquis.

\section{Conclusions}

In this study, we completed the physical map of the $S r 2$ locus in stem rust resistant cv Hope. Sequence comparison with susceptible CS revealed major haplotype divergence including deletion/insertion events carrying a large cluster of GLPs in Hope. The GLPs were however present in Marquis, a stem rust susceptible wheat not carrying Sr2. Haplotype divergence within hexaploid wheat may prevent rapid map-based identification of target genes in specific wheat genotypes even when high quality, reference genome sequence is available. Candidate genes within the $\mathrm{Sr} 2$ region are being evaluated for their capacity to confer stem rust resistance.

\section{Additional files}

\begin{abstract}
Additional file 1: Figure S1. Histogram of relative fluorescence (flow karyotype) from flow cytometric analysis of DAPI-stained mitotic chromosomes of Triticum aestivum cv. Hope. The flow karyotype consists of three composite peaks I - III representing groups of wheat chromosomes and peak of chromosome 3B. Inset: Images of flow-sorted 3B after FISH with a probe for GAA microsatellite (green). The chromosomes were counterstained by DAPI (blue). X axis: Relative fluorescence intensity. Y axis: Number of particles.
\end{abstract}

Additional file 2: Table S1. Primer sequences used for amplification of markers that were genetically mapped.

\section{Competing interests}

The authors declare that they have no competing interests.

\section{Authors' contributions}

RM, LT and WS conceived and designed the study. RM and LT performed experiments, RM, LT, JE and WS wrote the manuscript. SV and HB made the pooled BAC library and screened and sequenced clones. HŠ, MK and JD flow sorted chromosome $3 \mathrm{~B}$ and constructed the $3 \mathrm{~B}$ Hope BAC library. NU, JB, RA and XK sequenced clones and contributed bioinformatics expertise. All authors read and approved the final manuscript.

\section{Acknowledgements}

We are thankful to Xiaodi Xia and Sutha Chandramohan for providing excellent technical assistance. We are grateful to our colleagues Jarmila Číhalíková, Romana Šperková and Zdeňka Dubská for assistance with chromosome sorting and DNA amplification. JD, HK and HŠ were supported by the Czech Science Foundation (award no. P501/12/G090) and by the grant L01204 from the National Program of Sustainability I. This project (Triple rust initiative: CSP00161) is supported by the Grain Research and Development Corporation and is part of The Australian Cereal Rust Control Program.

\section{Author details}

${ }^{1}$ CSIRO Agriculture Flagship, Canberra, ACT 2601, Australia. ${ }^{2}$ INRA - CNRGV, 24 Chemin de Borde Rouge, Auzeville, CS 52627, 31326 Castanet Tolosan Cedex, France. ${ }^{3}$ Institute of Experimental Botany, Centre of the Region Haná for Biotechnological and Agricultural Research, Šlechtitelů 31, CZ-78371 
Olomouc, Czech Republic. ${ }^{4}$ Key Laboratory of Crop Germplasm Resources and Utilization, MOA/Institute of Crop Sciences, CAAS/The Key Facility for Crop Gene Resources and Genetic Improvement, Beijing 100081, PR China. ${ }^{5}$ Centre for Comparative Genomics, Murdoch University, Murdoch 6150WA, Australia. ${ }^{6}$ Current address: Australian Centre for Ancient DNA (ACAD), University of Adelaide, Adelaide, SA 5005, Australia.

Received: 3 August 2014 Accepted: 11 December 2014

Published online: 30 December 2014

\section{References}

1. Stokstad E: Deadly wheat fungus threatens world's breadbaskets. Science 2007, 315:1786-1787.

2. Wanyera R, Kinyua MG, Jin Y, Singh RP: The spread of stem rust caused by Puccinia graminis $\mathrm{f}$. sp. tritici, with virulence on $\mathrm{Sr} 31$ in wheat in Eastern Africa. Plant Dis 2006, 90:113

3. McFadden ES: A successful transfer of emmer characters to vulgare wheat. J Am Soc Agrc 1930, 22:1020-1034.

4. McIntosh RA, Luig NH, Baker EP: Genetic and cytogenetic Studies of stem rust, leaf rust, and powdery mildew resistances in Hope and related wheat cultivars. Aus J Bio Sci 1967, 20:1181-1192.

5. Knott DR: The inheritance of resistance to stem rust races 56 and 15B-1 L (Can.) in the wheat varieties Hope and H-44. Can J Genet Cytol 1968, 10:311-320.

6. Hare RA, McIntosh RA: Genetic and cytogenetic studies of durable adult-plant resistances in Hope and related cultivars to wheat rusts. Z Planzenzuchtung 1979, 83:350-367.

7. McIntosh RA: The role of specific genes in breeding for durable stem rust resistance in wheat and triticale. In Breeding strategies for resistance to the rusts of wheat. Edited by Simmonds NW, Rajaram S. Mexico: CIMMYT; 1988:1-9.

8. McIntosh RA, Park RF, Wellings CR: Wheat rusts: an atlas of resistance genes. East Melbourne: CSIRO Publications; 1995.

9. Rajaram S, Singh RP, Torres E: Current CIMMYT approaches in breeding wheat for rust resistance. In Breeding strategies for resistance to the rusts of wheat. Edited by Simmonds NW, Rajaram S. México: CIMMYT; 1988:101-118.

10. Roelfs AP: Genetic control of phenotypes in wheat stem rust. Ann Rev Phytopathol 1988, 26:351-367.

11. Singh RP, Hodson DP, Jin Y, Huerta-Espino J, Kinyua MG, Wanyera R, Njau P, Ward RW, Singh RP, Hodson DP, Jin Y, Huerta-Espino J, Kinyua MG, Wanyera R, Njau P, Ward RW: Current status, likely migration and strategies to mitigate the threat to wheat production from race Ug99 (TTKS) of stem rust pathogen. In CAB Reviews: Perspectives in Agriculture, Veterinary Science, Nutrition and Natural Resources. 2006. 1, No.054 doi:10.1079/PAVSNNR20061054.

12. Mago R, Tabe L, Mclntosh RA, Pretorius Z, Kota R, Paux E, Wicker T, Breen J, Lagudah ES, Ellis JG, Spielmeyer W: A multiple resistance locus on chromosome arm 3BS in wheat confers resistance to stem rust (Sr2), leaf rust (Lr27) and powdery mildew. Theor Appl Genet 2011, 123(4):615-623.

13. Singh RP, McIntosh RA: Complementary genes for reaction to Puccinia recondite tritici in Triticum aestivum. II Cytogenetic studies. Can I Genet Cytol 1984, 26:736-742.

14. Kota R, Spielmeyer W, McIntosh RA, Lagudah ES: Fine genetic mapping fails to dissociate durable stem rust resistance gene Sr2 from pseudo-black chaff in common wheat: (Triticum aestivum L.). Theor Appl Genet 2006, 112(3):492-499.

15. Vrána J, Kubaláková M, Šimková H, Číhalikiková J, Lysák MA, Doležel J: Flow-sorting of mitotic chromosomes in common wheat (Triticum aestivum L.). Genetics 2000, 156(4):2033-2041.

16. Doležel J, Vrána J, Cápal P, Kubaláková M, Burešová V, Šimková H: Advances in plant chromosome genomics. Biotech Adv 2014, 32:122-136.

17. Šafár J, Bartoš J, Janda J, Bellec A, Kubaláková M, Valárik M, Pateyron S, Weiserová J, Tušková R, Číhalíková J, Vrána J, Šimková H, Faivre-Rampant P, Sourdille P, Caboche M, Bernard M, Doležel J, Chalhoub B: Dissecting large and complex genomes: flow sorting and BAC cloning of individual chromosomes from bread wheat. Plant J 2004, 39(6):960-968.

18. Šimková H, Šafár̆ J, Kubaláková M, Suchánková P, Číhalíková J, Robert-Quatre H, Azhaguvel P, Weng Y, Peng J, Lapitan NLV, Ma Y, You FM, Luo M-C, Bartoš J, Doležel J: BAC Libraries from wheat chromosome 7D: efficient tool for positional cloning of aphid resistance genes. J Biomed Biotechnol 2011, 2011:302543. doi:10.1155/2011/302543.
19. Isidore E, Scherrer B, Bellec A, Budin K, Faivre-Rampant P, Waugh R, Keller B, Caboche M, Feuillet C, Chalhoub B: Direct targeting and rapid isolation of BAC clones spanning a defined chromosome region. Funct Integr Genom 2005, 5:97-103.

20. Ewing B, Green P: Base calling of automated sequencer traces using phred. II. Error probabilities. Genome Res 1998, 8(3):186-194.

21. Gordon D, Abajian C, Green P: Consed: a graphical tool for sequence finishing. Genome Re 1998, 8(3):195-202.

22. Huang $X$, Brutlag DL: Dynamic use of multiple parameter sets in sequence alignment. Nucleic Acids Res 2007, 35(2):678-686

23. Paux E, Sourdille P, Salse J, Saintenac C, Choulet F, Leroy P, Korol A, Michalak M, Kianian S, Spielmeyer W, Lagudah E, Somers D, Kilian A, Alaux M, Vautrin S, Bergès H, Eversole K, Appels R, Safar J, Simkova H, Dolezel J, Bernard M, Feuillet C: A physical map of the 1-gigabase bread wheat chromosome 3B. Science 2008, 322(5898):101-104.

24. Choulet F, Wicker T, Rustenholz C, Paux E, Salse J, Leroy P, Schlub S, Le Paslier MC, Magdelenat G, Gonthier C, Couloux A, Budak H, Breen J, Pumphrey M, Liu S, Kong X, Jia J, Gut M, Brunel D, Anderson JA, Gill BS, Appels R, Keller B, Feuillet $C$ : Megabase level sequencing reveals contrasted organisation and evolution patterns of the wheat gene and transposable element spaces. Plant Cell 2010, 22(6):1686-1701.

25. Davidson RM, Reeves PA, Manosalva PM, Leach JE: Germins: A diverse protein family important for crop improvement. Plant Sci 2009, 177:499-510.

26. Manosalva PM, Davidson RM, Liu B, Zhu X, Hulbert SH, Leung H, Leach JE: A Germin-like protein gene family functions as a complex quantitative trait locus conferring broad-spectrum disease resistance in rice. Plant Physiol 2009, 149(1):286-296

27. Mago R, Brown-Guedira G, Dreisigacker S, Breen J, Jin Y, Singh R, Appels R, Lagudah ES, Ellis J, Spielmeyer W: An accurate DNA marker assay for stem rust resistance gene Sr2 in wheat. Theor Appl Genet 2011, 122(4):735-744.

28. Krattinger SG, Lagudah ES, Spielmeyer W, Singh RP, Huerta-Espino J, McFadden $H$, Bossolini E, Selter LL, Keller B: A putative ABC transporter confers durable resistance to multiple fungal pathogens in wheat. Science 2009, 323(5919):1360-1363.

29. Fu D, Uauy C, Distelfeld A, Blechl A, Epstein L, Chen X, Sela H, Fahima T, Dubcovsky J: A kinase-START gene confers temperature-dependent resistance to wheat stripe rust. Science 2009, 323(5919):1357-1360.

30. Faris JD, Zhang Z, Lu HJ, Lu SW, Reddy L, Cloutier S, Fellers JP, Meinhardt SW, Rasmussen JB, Xu SS, Oliver RP, Simons KJ, Friesen TL: A unique wheat disease resistance-like gene governs effector-triggered susceptibility to necrotrophic pathogens. Proc Natl Acad Sci U S A 2010, 107(30):13544-13549.

31. Faris JD, Liu Z, Xu SS: Genetics of tan spot resistance in wheat. Theor Appl Genet 2013, 126(9):2197-2217.

32. He G, Luo X, Tian F, Li K, Zhu Z, Su W, Qian X, Fu Y, Wang X, Sun C, Yang J: Haplotype variation in structure and expression of a gene cluster associated with a quantitative trait locus for improved yield in rice. Genome Res 2006, 16(5):618-626.

33. Stahl EA, Dwyer G, Mauricio R, Kreitman M, Bergelson J: Dynamics of disease resistance polymorphism at the Rpm1 locus of Arabidopsis. Nature 1999, 400(6745):667-671.

34. Breen J, Bellgard M: Germin-like proteins (GLPs) in cereal genomes: gene clustering and dynamic roles in plant defence. Funct Integr Genom 2010, 10:463-476.

35. Druka A, Kudrna D, Kannangara CG, von Wettstein D, Kleinhofs A: Physical and genetic mapping of barley (Hordeum vulgare) germin-like CDNAs. Proc Natl Acad Sci U S A 2002, 99(2):850-855.

36. Zimmermann G, Bäumlein H, Mock H-P, Himmelbach A, Schweizer P: The multigene family encoding germin-like proteins of barley: regulation and function in basal host resistance. Plant Physiol 2006, 142(1):181-192.

37. Schweizer P, Christoffel A, Dudler R: Transient expression of members of germin-like gene family in epidermal cells of wheat confers disease resistance. Plant J 1999, 20(5):541-552. 